\section{Methods and logistics of a multidisciplinary survey of schoolchildren from Pelotas, in the Southern Region of Brazil}

\author{
Métodos e logística de um estudo multidisciplinar \\ com escolares de Pelotas, Sul do Brasil
}

\author{
Métodos y logística de un estudio multidisciplinar \\ con escolares de Pelotas, sur de Brasil
}

\section{Abstract}

This paper describes the methods of a multidisciplinary epidemiological survey conducted in schools in Pelotas, in the Southern Region of Brazil. This cross-sectional study evaluated a representative sample $(n=1,211)$ of eight to 12-year-old children attending public (15) and private (5) schools. Questionnaires were applied to parents to obtain information about socioeconomic and sociocultural characteristics. Children were interviewed to provide information on demographic characteristics, oral health behavior and physical activity habits. Oral health examinations were performed on the children and anthropometric data was collected to assess nutritional status. School principals responded a questionnaire about the social and physical environment of the school. A total of 1,744 children were eligible for the study; a response rate of $69.4 \%$ was achieved, with no significant differences between schools. The method used allowed investigators to obtain data on several health outcomes as well as on possible risk factors. This strategy optimizes the use of financial resources for research and promotes interprofessional collaboration.

Nutritional Status; Motor Activity; Oral Health

\author{
Marília Leão Goettems ${ }^{1}$ \\ Marcos Britto Correa 1 \\ Fabiana Vargas-Ferreira ${ }^{2}$ \\ Dione Dias Torriani 1 \\ Margarete Marques 3 \\ Marlos Rodrigues Domingues 3 \\ Pedro Curi Hallal 1 \\ Flávio Fernando Demarco 1,2
}

\section{Resumo}

O artigo detalha os métodos de um estudo epidemiológico multidisciplinar conduzido em escolas em Pelotas, Sul do Brasil. O estudo transversal incluiu uma amostra representativa $(n=$ 1.211) de crianças de 8 a 12 anos, em escolas públicas (15) e privadas (5). Questionários foram aplicados aos pais para obter informações socioeconômicas e culturais. As crianças foram entrevistadas, fornecendo informações demográficas, comportamentos de saúde bucal e prática de atividade física. Exame de saúde bucal foi realizado e medidas antropométricas aferidas para avaliação da condição nutricional. Diretores das escolas forneceram informações sobre o ambiente físico e social das escolas. Das 1.744 crianças elegíveis, a taxa de resposta foi $69,4 \%$ sem diferenças entre escolas. A metodologia proposta permitiu a obtenção de dados sobre diversos desfechos de saúde bem como sobre possiveis fatores de risco. Esta estratégia otimiza recursos financeiros de pesquisa e favorece a colaboração interprofissional.

Estado Nutricional; Atividade Motora; Saúde Bucal 


\section{Background}

Public health policies no longer address diseases in an isolated manner. In an era of evidencebased health care, the common risk factors approach is an important component of effective health interventions 1 . This approach requires an adequate balance between the assessment of both individual-level factors and the social environment in which individual health behavior is developed and sustained 2 .

Oral disease is considered one out of six components of major chronic diet-related diseases and is an important public health concern with significant cost implications 3 . The same oral and general health behaviors have been shown to occur among certain population subgroups ${ }^{4}$ and it is known that oral health inequalities mirror those in general health. The universal social gradient in both general and oral health highlights the underlying influence of psychosocial, economic, environmental and political determinants 5 .

The World Health Organization (WHO) recommends that oral health programs should be linked to the main health concerns of the community, targeting oral and general health problems ${ }^{6}$. Some lifestyle behaviors associated with an increased risk of obesity, such as unhealthy habits and physical inactivity, are also associated with oral health diseases, including dental caries, considered to be the principal oral health problem around the world 7,8,9, dental erosion 10,11 and traumatic dental injuries 12,13. Environment may also be a factor that influences obesity and dental disease 14 . The school environment may contribute to poor food choices, ineffective lifestyle education and inadequate levels of physical activity 15,16 and thus influence the condition of children's health. The WHO presents strong arguments for oral health promotion in schools, pointing out that lifelong oral health related behavior, beliefs and attitudes are developed during the formative years of childhood and adolescence.

The effective formulation of public policies to address diseases with common risk factors requires methodologically appropriate multidisciplinary epidemiological studies. There is scarce information on the relationship between the school environment, physical activity, nutritional status and oral disease and assessment methods are not adequately described. Also, although cross-sectional studies are relatively common, papers describing the methodological challenges faced by studies and practical solutions to the possible difficulties were not found. It is important to highlight that financial support for research is limited, especially in developing countries, and the assessment of different health outcomes under the same epidemiologic survey may help optimize the use of public resources 17. As part of a collaboration between three post-graduate programs (Epidemiology, Dentistry and Physical Education), this paper aims to provide a useful contribution to the field of oral disease by describing the methodological and logistical challenges concerning a multidisciplinary study conducted in Pelotas, Rio Grande do Sul State, in the Southern Region of Brazil.

\section{Methods}

This multidisciplinary, cross-sectional study assessed the social and physical environment of schools in Pelotas and the oral health and nutritional status, and physical activity levels among pupils. The city has a population of approximately 305,696 people, of which 25,628 are children aged between eight and 12 years (http://www. ibge.gov.br/censo2010/primeiros_dados_di vulgados $/$ index.php?uf $=43.18$, accessed on $10 /$ Mar/2011).

\section{Sampling procedure}

Participants were children aged between eight and 12 years attending both private and public schools. A two-stage stratified sample design was adopted for sample selection. The minimum sample size needed was estimated using the Epi Info 6.0 software (Centers for Disease Control and Prevention, Atlanta, USA), considering a prevalence of $10 \%$ of the main outcome (dental trauma), standard error of $\leq 3$ percentage points and a $95 \%$ confidence level. Since a cluster sample selection was adopted, the design effect was estimated at 2 . The sample was increased by $20 \%$ (to 922 children) to account for non-response. There are 25 private and 91 public schools in Pelotas for children in this age range. In order to ensure proportionality, five private and 15 public schools were randomly selected by using a probability selection method where probability was proportional to school size. This is considered an adequate number of cluster-sample points to ensure variability between characteristics ${ }^{18}$. In each school, five $2^{\text {nd }}$ to $6^{\text {th }}$ grade classes were randomly selected and all children enrolled in these classes were initially eligible for the study. Physically and/or mentally disabled children were excluded from the study.

\section{Data collection}

Data was collected using a parent's questionnaire, interviews, oral clinical examinations and 
anthropometric measurements with the children, together with an assessment of the social and physical environment of the school. An initial visit was made by supervisors to schools to invite children to participate. A further two visits were made to obtain authorization and collect the completed questionnaire during which other children who had not been present during the other visits were also given the opportunity to participate.

Schools were visited by the research team between September and November 2010 to carry out interviews, oral clinical examinations and anthropometric measurements with the children whose parents had returned the informed consent form. Schools were visited until no more than $10 \%$ of children were absent from data collection. The Research team was composed of six graduate dental students, who performed the clinical oral examinations, one physical educator, who performed the anthropometric measurements, and nine annotators. Two graduate students supervised fieldwork and a secretary was hired to contact schools and to purchase and organize the necessary research materials.

The previously validated data collection methods are shown in Figure 1. Copies of the questionnaires are available upon request. All data was collected during morning and afternoon class periods.

\section{Procedures}

\section{- Parent interviews}

A previously tested questionnaire designed to obtain socioeconomic and sociocultural information on the children and their families was

\section{Figure 1}

Data collected during the survey. Pelotas, Rio Grande do Sul State, Brazil, 2010.
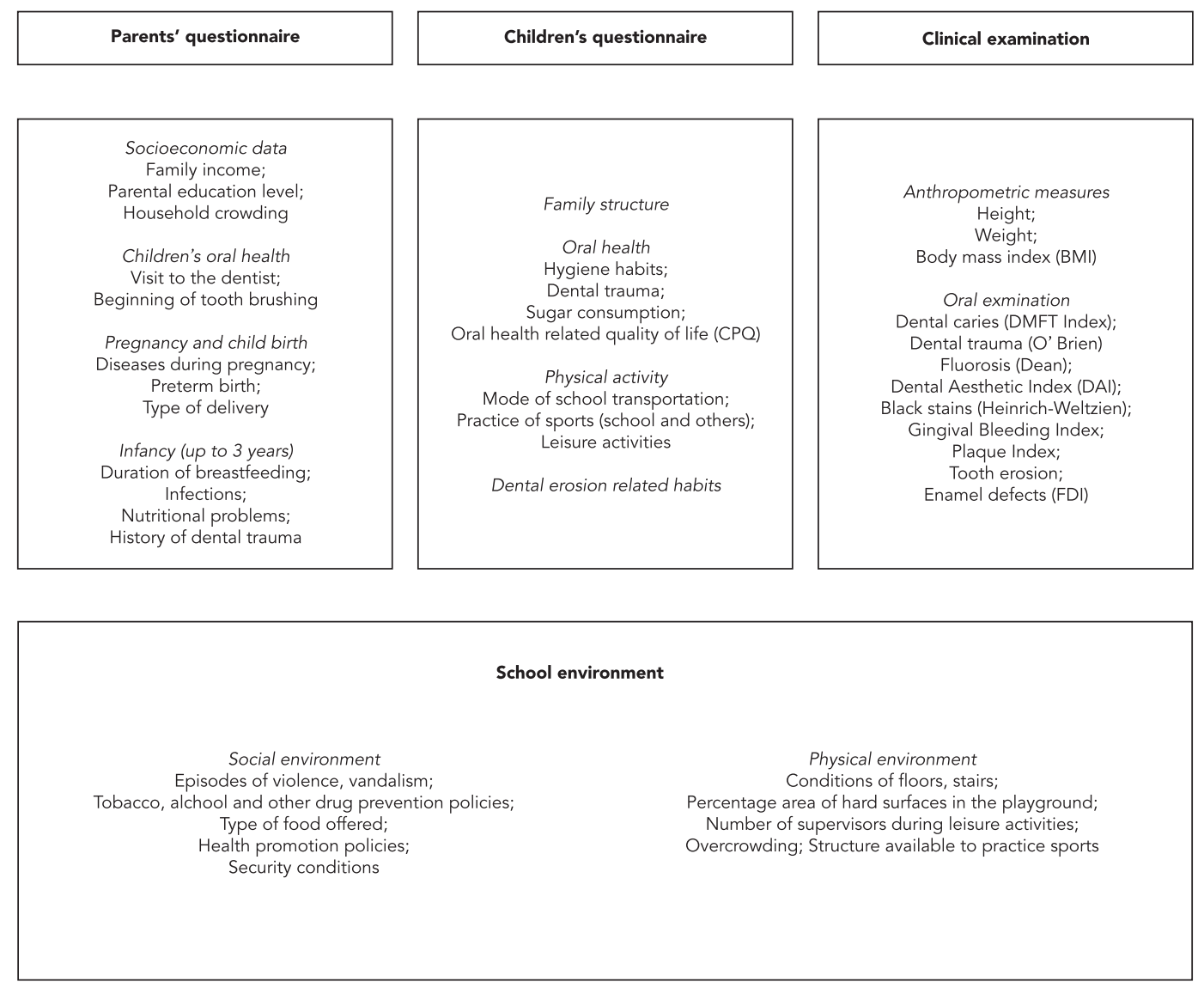
sent to parents. The level of parents' education was evaluated in terms of years of formal education and family income was measured in Brazilian Reais (R\$). Information on family structure and number of persons living in a household was also collected.

Parents were asked whether their children had had a dental appointment and when they began toothbrushing with fluoride dentifrice. Information was also collected regarding the following aspects: whether mothers had received antenatal care; maternal health during pregnancy (gestational diabetes mellitus, infections, and nutritional problems); type of delivery (normal or cesarean); childbirth (preterm or full-term); and child health status during early childhood (length of breastfeeding, presence of infections and nutritional problems, history of dental trauma). With regard to answers related to infections and nutritional problems, parents were asked to inform if a doctor or other health professional had diagnosed these problems.

\section{- Children's questionnaires}

Previously trained interviewers conducted questionnaires with all children that included questions regarding the following: demographic characteristics (age and sex); family structure; history of dental trauma; dental pain in the last six months and four weeks; dental fear, child's oral health related quality of life (Child Perceptions Questionnaire 8-10 and 11-14 19, according to age group); self-perceived oral health; oral hygiene habits (frequency of tooth brushing, use of dental floss and use of mouthwash); and information on dietary practices including sugar consumption, eating before sleep, consumption of soft drinks (full sugar and light) and fruit juice.

Information on lifestyle was collected using a previously tested physical activity questionnaire 20 that addressed commuting to and from school or work, leisure-time physical activities and details regarding children's habits in order to categorize physical activity levels as adequate or inadequate (<300 minutes/week)

\section{- Anthropometric measurements}

Height was measured to the nearest $0.1 \mathrm{~cm}$ with a portable stadiometer and weight was measured with individuals wearing light clothing and no shoes to the nearest $0.1 \mathrm{~kg}$ using a digital scale (WHO). Body Mass Index (BMI) was calculated as weight in kilograms divided by height in meters squared. Participants were classified as normal overweight or obese according to sex and agespecific BMI cut-off points 21 .

\section{- Oral clinical examination}

The clinical examination was performed in regular school chairs by six post-graduate dental students using protective equipment (gloves, mask and apron), artificial light, dental mirror and CPI probes, following procedures recommended by the WHO 22: initial assessment of periodontal condition using the Plaque Index 23, which considers the presence of plaque on tooth surfaces, and the Gingival Bleeding Index 23, which assesses the presence of bleeding after probing four sites in each tooth (mesiobuccal, midbuccal, distobuccal and lingual). For both indexes six teeth were evaluated - first molars and incisors of the diagonal quadrants. The quadrants selected for examination were drawn for each selected school.

After the oral hygiene evaluation, teeth were cleaned with dental gauze as and when necessary and dental caries were assessed using the DMFT (Decayed, Missing and Filled Teeth) Index 22, which measures lifetime dental caries experience in permanent dentition. The O'Brien Index 24 was used to evaluate the presence of dental trauma, treatment need and the presence of treatment. Malocclusions were evaluated using the Dental Aesthetic Index 22, which considers a combination of measures to determine the degree of malocclusion and need for treatment.

Fluorosis was assessed using the Dean Index 25 and tooth erosion was evaluated using the O'Sullivan Index 26, which assesses the erosion of incisors by surface, severity and area of surface affected. Enamel defects were evaluated using the FDI Index for Enamel Defects 27 on the buccal surfaces of teeth 14, 13, 12, 11, 21, 22, 23, 24, 36 and 46 . The presence of black stains was considered when two neighboring teeth presented black dots parallel to the gingival margin or covering up to one third of the crown with difficult removal 28.

\section{- The social and physical environment of the school}

To evaluate the physical environment of the schools, a single evaluator collected data on the condition of the floor, stairs, playground area, classrooms, corridors and bathrooms, number of students during playtime, and number of supervisors present during the break. Conditions were classified as bad or regular, based on Brazilian government recommendations for a safe school environment 29,30 and the criteria of a previous study 31 . The area of the playground was measured in meters with a 50-meter measuring tape. The area of hard surfaces (cement, asphalt) was 
classified into the following groups: up to $33 \%$; $34 \%$ to $66 \%$; over $66 \%$. Overcrowding in playgrounds was assessed based on the number of pupils present during playtime divided by playground area (students $/ \mathrm{m}^{2}$ ) and the number of supervisors per 100 students.

The social environment was assessed using a questionnaire based on a questionnaire used in the National Survey of Students' Health (PeNSE) 32 that was conducted with school administrators and contained 40 questions addressing the following topics: (1) structure and support for daily personal hygiene (bathrooms, changing rooms); (2) availability of school canteen and types of food available; (3) spaces for physical activity during classes and leisure time (i.e. weekends) for both students and families as well as the existence of extra-curricular activities (free of charge or paid); (4) school security, presence and type of fencing around the school, need for police security, occurrence of acts of violence (physical, verbal, bullying) and vandalism among students or against the school population or structure, existence of gangs, episodes involving fire arms; (5) alcoholic drinks, tobacco and drugs and episodes of licit and illicit substance use within the school environment by students, teachers and staff; (6) school syllabus - inclusion of topics such as tobacco, drugs, peace and violence prevention, physical activity, healthy eating, sexually transmitted diseases (STDs); (7) anti-tobacco policies, participation of the community in school decision making; (8) presence of students with hearing or visual impairments, mental or physical disabilities.

The questionnaire used to evaluate school facilities and sports equipment, based on a questionnaire used by Kremer et al. 33 during a similar study in Pelotas, included questions about the number of teachers and physical education teachers, number of hours of physical education classes per week, indoor facilities (courts and gyms) and other available equipment.

The questionnaire used to assess extra-curricular activities identified which activities were on offer, where they were carried out, who promoted the activities, if they were paid or free of charge, and ease of pupil participation in such activities. The questionnaire was developed by the researchers and improvements were made following discussions with physical education teachers who suggested specific alterations to increase pupil understanding of questions.

\section{- Pre-tests of questionnaires and interviews}

A pre-test of the questionnaire was performed in the School of Dentistry with mothers and 10 children in the same age group as the study population. The questionnaire showed satisfactory levels of acceptability and ease of completion; however, certain adjustments to the categorization of variables of the parents' questionnaire were made to facilitate understanding.

For the purposes of informing schools how much time children would be absent from class, the duration of data collection, comprising the children's interview (mean duration of $10 \mathrm{~min}$ utes) and clinical examination, was estimated to be approximately 30 minutes.

\section{- Calibration methods}

To ensure study reliability, a training and calibration process was performed with the examiners responsible for conducting the oral examination and anthropometric measurements prior to carrying out fieldwork. During this stage team members received a manual containing information regarding the instruments used and instructions about data collection for use during data collection. With regard to the oral health examination, this process was divided in four parts:

\section{a) Theoretical and practical training}

The examiners and assistants received four-hours of initial theoretical training where the study supervisors explained the indexes used through a presentation with images of each evaluated condition. During this stage the examiners also discussed specific diagnostic criterion therefore facilitating the fieldwork team to reach agreement on criteria.

After this activity, the fieldwork team practiced carrying out the examination for a period of three hours with children of the same age group from a school not included in the study, therefore ensuring that these children would not be included in the study sample. During this stage, each of the six pairs of examiners/annotators took turns to evaluate two groups of five children. At the end of each turn, the examiners met with the coordinators to compare records and discuss discrepancies and when necessary children were examined again. This phase was important for examiners and annotators to familiarize themselves with the dynamics of the examination process.

\section{b) Clinical calibration}

The calibration exercise took place in the same school where the theoretical and practical training was performed. Four groups of five children aged between eight and 12 years, totaling 20 
children, were examined by the six dentists and one gold standard examiner with previous experience of epidemiologic studies. During this phase of the process no contact was allowed between the examiners or between the examiners and the supervisors. Although all the oral health indexes mentioned above were examined in children from the study sample, for the evaluation of interexaminer reliability only the DMFT (dental caries) and Dental Aesthetic (malocclusion) indexes were physically examined; the examination of the remaining indexes, considered rarer conditions, were subject to an in lux calibration (see below). Dental plaque and gingival bleeding were included in the calibration exercise, but no analysis of agreement was performed due to the difficulties involved in maintaining the condition unaltered during the series of examinations.

\section{c) Calibration in lux}

The calibration process for dental trauma, fluorosis, black stains, tooth erosion and enamel defects was performed in lux, using a similar method to that used by the 2010 Brazilian Oral Health Survey. This method provides an alternative for the calibration of relatively small samples where conditions have low prevalence or large variability. For example, the prevalence of dental trauma is only $10 \%$ and therefore in a calibration sample of 20 children only two children would be expected to have this condition. Considering that most injuries are enamel fractures, there is a high probability that examiners would not observe the other aspects of dental erosion considered by the O'Brien Index. Thus, the result of a clinical exercise may not reflect the true ability of an examiner to correctly evaluate clinical conditions according to specific criteria. The in lux process consists of the projection of 20 to 30 images showing different possible variations in the condition, thus testing the examiners in all examination possibilities. After seeing the first 10 images as a group, the examiners met with the coordinators to compare records and discuss discrepancies as with the clinical calibration process. After this phase, a sequence of images was presented to each examiner alone and a two minute interval between each image was given to observe the image and note down the condition. The process lasted approximately 60 minutes for each condition, giving a total of five hours for the whole exercise. At the end of activities the results were compared with a gold standard record.

\section{d) Analysis of agreement}

Agreements between the examiners and gold standard were calculated using kappa statistics. The simple kappa coefficient was used for dichotomous and categorical variables while the weighted kappa was used for ordinal variables. Kappa values above 0.6 were considered satisfactory.

\section{- Quality control}

Quality control was performed by revisiting each school to conduct a shorter version of the interview with 10 children.

\section{Ethical aspects}

The project was approved by the Human Ethics Research Committee of the Pelotas Federal University (protocol 160/2010) and by the Education Department. Parents received a letter through their children explaining study aims, confidentiality and requesting parental consent for their child's participation. Children received toothbrushes and toothpaste and parents were informed of the oral health status of their children. Those who needed dental treatment were referred to the School of Dentistry of the Pelotas Federal University, where a special program involving professors, post-graduate and undergraduate students was developed to perform the required treatment.

\section{Data analysis}

Data was entered twice into an EpiData (The EpiData Association, Odense, Denmark) database. Automatic checks for consistency range and validation of duplicate files was performed in order to detect mistakes. Data analysis was carried out using Stata 10.0 (Stata Corp., College Station, USA). Descriptive statistics were used to characterize the sample.

\section{Results}

Table 1 shows the results of the calibration process for clinical variables by percentage agreement and kappa values. The six examiners achieved the minimum acceptable kappa value (0.6) for all conditions. Percentage agreements in general showed values that were greater than the kappa values and this difference was substantial for some variables such as the DMFT Index (96 to $98 \%$ of agreement and kappa range of 0.62-0.79). 
Table 1

Minimal and maximum agreement values and kappa statistics resulting from the calibration process by oral health outcomes $(n=22)$.

\begin{tabular}{lcc}
\hline Oral health variable & Agreement range & Mean kappa value (range) \\
\hline DMFT Index & $96-98$ & $0.74(0.62-0.79)$ \\
DAl & $79-95$ & $0.72(0.65-0.91)$ \\
O'Brien Index & $95-98$ & $0.92(0.89-0.95)$ \\
Tooth erosion & $60-68$ & $0.60(0.60-0.60)$ \\
Fluorosis & $67-81$ & $0.84(0.81-0.89)$ \\
Enamel defects & $81-90$ & $0.76(0.71-0.82)$ \\
Black stains & $83-100$ & $0.70(0.64-1.00)$ \\
\hline
\end{tabular}

DAI: Dental Aesthetic Index; DMFT: decayed, missing and filled teeth.

Figure 2 is a flowchart of the study. A total of 1,744 children were eligible for the study, of which 418 (24\%) did not present the informed consent form signed by parents. Of those children with parental consent to participate in the study, 105 (7.9\%) were lost because they were absent from school during data collection. The final response rate was therefore $69.4 \%$, giving a total sample of 1,211 children. Table 2 shows the differences in response rates between the different schools. The total response rate was $67.5 \%$ in private schools and $70.9 \%$ in public schools. In private schools $71.2 \%$ of children's parents signed and returned the informed consent form, compared to $78.9 \%$ in public schools. Absence during data collection days was higher in public schools (8.5\%) than in private schools (5.3\%).

The parent's questionnaire was answered by mothers in $91.52 \%$ of cases, by fathers in $2.35 \%$ of cases and by a guardian or carer in $6.13 \%$ of cases. Table 3 shows the demographic and socioeconomic characteristics of the sample. In some cases data regarding certain characteristics was missing because parents failed to fully complete the form. Family income was the variable with the highest number of missing values (174), followed by father's schooling (124).

Around $20 \%$ of the children in the sample were from private schools. This percentage is similar to the proportion of children studying in private schools in Pelotas. Differences in family income, maternal schooling, family structure and skin color by type of school (private or public) are shown in Table 3.

\section{Discussion}

This paper details the methods of a multidisciplinary study of children's oral health condi- tion, nutritional status and level of physical activity, and the social and physical environment of schools in Pelotas in 2010. Although scarce, multidisciplinary studies have the following important advantages: the fact that data is collected only once minimizes the burden on study participants, including the amount of time pupils spend absent from class, and reduces the cost of data collection; this method also provides a more robust evaluation of children's health.

Despite the fact that health research funding in Brazil has grown in recent years, financial resources are still limited for evaluations of different health outcomes across the country's different geographical regions. Therefore, the investigation of a number of different health outcomes in a single epidemiologic survey helps to optimize the use of available resources. Also, this kind of approach promotes interprofessional collaboration that helps to tackle and overcome methodological challenges. Apart from the scientific papers resulting from this study, a report on the oral and physical condition of the children was delivered to the educational services department and the results of this study were made available to the general population through a summary of findings published in the local newspaper.

This study shows the feasibility of carrying out an assessment of this nature with good internal and external validity. The number of children examined by this study was greater than the minimum required sample size for such a study; in this respect, it is important to note that the minimum sample size was calculated for each outcome included in this study. Furthermore, intra and inter-reliability was satisfactory for all conditions assessed by this study. Training examiners to detect rare diseases is a challenge for oral health studies because the majority of individuals that participate in training exercises are healthy 
Figure 2

Flowchart of the study. Pelotas, Rio Grande do Sul State, Brazil, 2010.

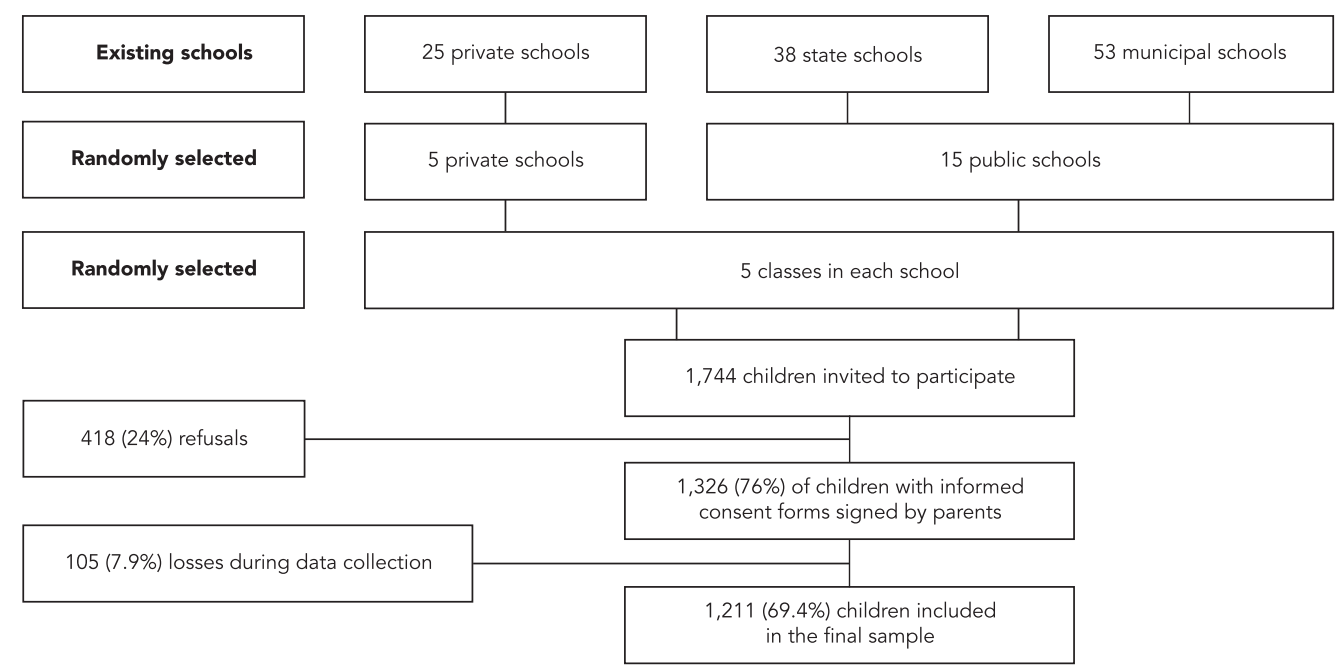

Table 2

Response rate for different sampling points $(n=20)$.

\begin{tabular}{|c|c|c|c|c|}
\hline School name & $\begin{array}{l}\text { Delivered } \\
\quad[\mathrm{n}]\end{array}$ & $\begin{array}{c}\text { Parent's agreement } \\
\text { [n (\%)] }\end{array}$ & $\begin{array}{l}\text { Absents } \\
\text { [n (\%)] }\end{array}$ & $\begin{array}{c}\text { Response rate } \\
\text { [n (\%)] }\end{array}$ \\
\hline Private & 386 & $268(71.2)$ & $14(5.3)$ & $254(67.5)$ \\
\hline Emanuel & 55 & $47(85.5)$ & $4(8.5)$ & $43(78.2)$ \\
\hline Castro Alves & 67 & $54(80.6)$ & $2(3.7)$ & $52(77.6)$ \\
\hline São Francisco de Assis & 103 & 75 (72.8) & $2(2.7)$ & $73(70.9)$ \\
\hline Gonzaga & 113 & $62(54.9)$ & $5(8.1)$ & $57(50.4)$ \\
\hline Nossa Senhora da Luz & 48 & $30(62.5)$ & $1(3.3)$ & $29(60.4)$ \\
\hline Public (state and municipal) & 1,358 & $1,058(78.9)$ & $91(8.5)$ & 957 (70.9) \\
\hline Procópio Duval Gomes Freitas & 83 & $78(94.0)$ & $7(9.0)$ & $71(85.5)$ \\
\hline Independência & 113 & $44(38.9)$ & $2(4.5)$ & $42(37.7)$ \\
\hline Cassiano do Nascimento & 119 & $84(70.6)$ & $3(3.6)$ & $81(68.1)$ \\
\hline Jacob Brod & 86 & $52(60.5)$ & $3(5.8)$ & $49(57.0)$ \\
\hline Nossa Senhora do Carmo & 59 & $42(71.2)$ & $4(9.5)$ & $38(64.4)$ \\
\hline Santo Antônio & 121 & $83(68.6)$ & $6(7.2)$ & $77(63.6)$ \\
\hline Luiz Carlos Corrêa da Silva & 101 & $95(94.1)$ & $0(0.0)$ & $95(94.1)$ \\
\hline Brum Azevedo & 81 & $68(84.0)$ & $6(8.8)$ & $52(64.2)$ \\
\hline Nossa Senhora de Fátima & 144 & $133(92.4)$ & $18(13.5)$ & 115 (79.9) \\
\hline Sagrado Coração de Jesus & 90 & $88(97.8)$ & $12(13.6)$ & $76(84.4)$ \\
\hline Antônio Joaquim Dias & 95 & $50(52.6)$ & $0(0.0)$ & $50(52.6)$ \\
\hline Cecília Meireles & 70 & $53(75.7)$ & $9(17.0)$ & $44(62.9)$ \\
\hline Círculo Operário Pelotense & 49 & $41(83.7)$ & $4(9.8)$ & $37(75.5)$ \\
\hline Luiz Augusto Assumpção & 95 & $95(100.0)$ & $8(8.4)$ & $87(91.6)$ \\
\hline Dr. Francisco Campos Barreto & 52 & $52(100.0)$ & $9(17.3)$ & $43(82.7)$ \\
\hline Total & 1,744 & $1,326(76.0)$ & $105(7.9)$ & $1,211(69.4)$ \\
\hline
\end{tabular}


Table 3

Demographic and socioeconomic characteristics of the sample according to school type $(n=1,211)$.

\begin{tabular}{|c|c|c|c|}
\hline Variable & Private [n (\%)] & Public [n (\%)] & Total [n (\%)] \\
\hline \multicolumn{4}{|l|}{ Sex } \\
\hline Male & $116(45.9)$ & $458(47.8)$ & $574(47.4)$ \\
\hline Female & $137(54.1)$ & $500(52.2)$ & $637(52.6)$ \\
\hline \multicolumn{4}{|l|}{ Skin color } \\
\hline White & $219(92.4)$ & $637(74.4)$ & $856(70.7)$ \\
\hline Light-skinned black & $3(1.3)$ & $125(13.3)$ & $128(10.6)$ \\
\hline Dark-skinned black & $15(7.9)$ & $174(18.6)$ & $189(15.6)$ \\
\hline Amerindian & - & $2(0.2)$ & $2(0.2)$ \\
\hline \multicolumn{4}{|l|}{ Age (years) } \\
\hline 8 & $54(21.3)$ & $128(13.4)$ & $182(15.0)$ \\
\hline 9 & $79(31.2)$ & $233(24.3)$ & $312(27.8)$ \\
\hline 10 & $54(21.3)$ & $241(25.2)$ & $295(24.4)$ \\
\hline 11 & $53(21.0)$ & $206(21.5)$ & $259(21.4)$ \\
\hline 12 & $13(5.1)$ & $150(15.7)$ & $163(13.5)$ \\
\hline \multicolumn{4}{|l|}{ Family income (quartiles) $[R \$]$} \\
\hline $4[1,231.00$ to $12,000.00]$ & $275(32.4)$ & $4(2.1)$ & $279(26.9)$ \\
\hline $3[741.00$ to $1,230.00]$ & $236(27.8)$ & $5(2.7)$ & $241(23.2)$ \\
\hline 2 [511.00 to 740.00$]$ & $234(27.5)$ & $37(19.8)$ & $271(26.1)$ \\
\hline 1 [Up to 510.00$]$ & $105(12.4)$ & $141(75.4)$ & $246(23.7)$ \\
\hline \multicolumn{4}{|l|}{ Maternal schooling (years) } \\
\hline $0-8$ & $22(8.8)$ & $531(57.4)$ & $553(47.0)$ \\
\hline $9-11$ & $82(32.7)$ & $293(31.7)$ & 375 (31.9) \\
\hline$\geq 12$ & $147(58.6)$ & $101(10.9)$ & $248(21.1)$ \\
\hline \multicolumn{4}{|l|}{ Family structure } \\
\hline Nuclear & $177(70.5)$ & $563(58.8)$ & $740(61.3)$ \\
\hline Single parent & $52(20.7)$ & $280(29.3)$ & $332(27.5)$ \\
\hline Reconstituted family & $10(4.0)$ & $67(7.0)$ & $77(6.4)$ \\
\hline Other responsible & $12(4.8)$ & 47 (4.9) & $59(4.4)$ \\
\hline
\end{tabular}

and this fact may influence kappa scores. To address this problem we used an in lux calibration process as described above. This methodology is considered adequate for detecting rarer conditions and could be adopted by future studies.

The study method involved visiting schools at least three times to remind children to give the informed consent form to their parents and visiting schools as many times as necessary to perform data collection. These strategies contributed to achieving a satisfactory response rate and therefore sampling bias is unlikely to be present. However, the parent response rate by school ranges from 38.9 to $100 \%$. A possible reason for this was the lack of participation of school principals and teachers in stimulating children and parents to participate in the study in certain schools. Future studies should be attentive to this type of situation so as to avoid such variations.
The number of sampling points ensures sample variability 18 , thus making it representative of the general school pupil population of Pelotas. Furthermore, according to the local education authority, almost $100 \%$ of the children in urban areas are enrolled in schools, thus ensuring the representativeness of the study sample. The use of validated instruments and questionnaires is another major strength of the study. For example, the level of physical activity was obtained by means of a questionnaire previously developed and validated in the city of Pelotas and thus adequate to the local reality. Regarding oral health conditions, the selected criteria allow comparison with previous studies.

The BMI of each child was calculated to assess nutritional status. BMI is commonly used to measure of adiposity among adults because it is 
easy to calculate, quick and noninvasive. However, its use in children and adolescents is controversial and should always take into account age and gender. In light of this, we used Cole's criteria to estimate nutritional status which considers the age and sex of individuals 21 .

Aside from the socioeconomic characteristics of the children's families, this study also assessed the physical and social environment of the schools. The circumstances in which people live and work has a profound impact on their health and well-being ${ }^{34}$. In the case of children, that spend a large part of their day at school, the social and physical environment of the school may also be a factor that influences health. Literature on instruments for assessing the physical and social environment of schools is scarce, and the methods used by the present study may prove useful for future studies that address this topic.

It is recognized that the cross-sectional nature of the study limits our ability to draw causal inferences. However, this type of study is of utmost importance when estimating prevalence of outcomes in a representative population sample and allows the assessment of multiple outcomes and risk factors. The data presented will be a use- ful input to public health planning and hypothesis generation and will help widen understanding of disease etiology 35 . Furthermore, this data may be used as an input to longitudinal studies of this sample or to monitor oral health conditions among children in Pelotas over time.

\section{Conclusions}

In conclusion, this study emphasizes the importance of a multidisciplinary approach to the study of child health outcomes. The strategy adopted optimizes the use of financial resources for research and promotes inter-professional collaboration. The method used by this study allowed investigators to obtain data on several different health outcomes and on possible risk factors. The present study will help identify the factors associated with the presence of oral health problems, poor nutritional status and inadequate level of physical activity among this population. Finally, the results are an important input to planning for health interventions directed at reducing the prevalence of major dental health problems diagnosed using a common risk approach.

\section{Resumen}

El artículo detalla los métodos de un estudio epidemiológico multidisciplinar llevado a cabo en escuelas en Pelotas, sur de Brasil. El estudio transversal incluyó una muestra representativa $(n=1.211)$ de niños de 8 a 12 años, en escuelas públicas (15) y privadas (5). Los cuestionarios fueron administrados a los padres para obtener información socioeconómica y cultural. Los niños fueron entrevistados, proporcionando información demográfica, comportamientos de salud bucal y práctica de actividad física. Se realizaron un examen de salud bucal y medidas antropométricas para la evaluación de la condición nutricional. Directores de escuelas proporcionaron información sobre el ambiente físico y social de las escuelas. De los 1.744 niños elegibles, la tasa de respuesta fue de un $69,4 \%$ sin diferencias entre escuelas. La metodología propuesta permitió la obtención de datos sobre diversas soluciones de salud, así como sobre posibles factores de riesgo. Esta estrategia optimiza recursos financieros de investigación y favorece la colaboración interprofesional.

Estado Nutricional; Actividad Motora; Salud Bucal 


\section{Contributors}

M. L. Goettems, M. B. Correa, F. Vargas-Ferreira, D. D. Torriani and M. Marques participated in study design and coordination and in drafting this manuscript. M. R. Domingues participated in study design and drafted this manuscript. P. C. Hallal and F. F. Demarco were responsible for study conception, participated in study design and coordination and drafted this manuscript.

\section{Acknowledgments}

The authors are grateful to the CPNq for the research funding grant \#402350 for the PI (F.F.D.) and PhD scholarship (M.L.G.). Moreover, the authors would like to thank Colgate for the oral hygiene kits distributed during fieldwork.

\section{References}

1. Sheiham A, Watt RG. The common risk factor approach: a rational basis for promoting oral health. Community Dent Oral Epidemiol 2000; 28:399-406.

2. Sanders AE, Spencer AJ, Slade GD. Evaluating the role of dental behaviour in oral health inequalities. Community Dent Oral Epidemiol 2006; 34:71-9.

3. de Silva-Sanigorski AM, Calache H, Gussy M, Dashper S, Gibson J, Waters E. The VicGeneration study: a birth cohort to examine the environmental, behavioural and biological predictors of early childhood caries: background, aims and methods. BMC Public Health 2010; 10:97.

4. Sanders AE, Spencer AJ, Stewart JF. Clustering of risk behaviours for oral and general health. Community Dent Health 2005; 22:133-40.

5. Watt RG. Strategies and approaches in oral disease prevention and health promotion. Bull World Health Organ 2005; 83:711-8.

6. Petersen PE, Kwan S. Evaluation of communitybased oral health promotion and oral disease prevention: WHO recommendations for improved evidence in public health practice. Community Dent Health 2004; 21 (4 Suppl):319-29.

7. Willershausen B, Haas G, Krummenauer F, Hohenfellner K. Relationship between high weight and caries frequency in German elementary school children. Eur J Med Res 2004; 9:400-4.
8. Larsson B, Johansson I, Hallmans G, Ericson T. Re lationship between dental caries and risk factors for atherosclerosis in Swedish adolescents? Community Dent Oral Epidemiol 1995; 23:205-10.

9. Hilgers KK, Kinane DE, Scheetz JP. Association between childhood obesity and smooth-surface caries in posterior teeth: a preliminary study. Pediatr Dent 2006; 28:23-8.

10. Petersen PE. The World Oral Health Report 2003: continuous improvement of oral health in the 21st century: the approach of the WHO Global Oral Health Programme. Community Dent Oral Epidemiol 2003; 31 Suppl 1:3-23.

11. Vargas-Ferreira F, Piovesan C, Praetzel JR, Mendes FM, Allison PJ, Ardenghi TM. Tooth erosion with low severity does not impact child oral health-related quality of life. Caries Res 2010; 44:531-9.

12. Nicolau B, Marcenes W, Sheiham A. Prevalence, causes and correlates of traumatic dental injuries among 13-year-olds in Brazil. Dent Traumatol $2001 ; 17: 213-7$

13. Petti S, Cairella G, Tarsitani G. Childhood obesity: a risk factor for traumatic injuries to anterior teeth. Endod Dent Traumatol 1997; 13:285-8.

14. Palmer CA. Dental caries and obesity in children: different problems, related causes. Quintessence Int 2005; 36:457-61. 
15. Luepker RV. How physically active are American children and what can we do about it? Int J Obes Relat Metab Disord 1999; 23 Suppl 2:S12-7.

16. Yackel EE. An activity calendar program for children who are overweight. Pediatr Nurs 2003; 29:17-22.

17. Pacheco-Santos LM, Moura EC, Barradas Barata RC, Serruya SJ, da Motta ML, Silva Elias FT, et al. Fulfillment of the Brazilian agenda of priorities in health research. Health Res Policy Syst 2011; 9:35.

18. Bennett S, Woods T, Liyanage WM, Smith DL. A simplified general method for cluster-sample surveys of health in developing countries. World Health Stat Q 1991; 44:98-106.

19. Goursand D, Paiva SM, Zarzar PM, Ramos-Jorge ML, Cornacchia GM, Pordeus IA, et al. Cross cultural adaptation of the Child Perceptions Questionnaire 11-14 (CPQ11-14) for the Brazilian Portuguese language. Health Qual Life Outcomes 2008; 6:2.

20. Bastos JP, Araújo CLP, Hallal PC. Prevalence of insufficient physical activity and associated factors in Brazilian adolescents. J Phys Act Health 2008; 5:777-94.

21. Cole TJ, Bellizzi MC, Flegal KM, Dietz WM. Establishing a standard definition for child overweight and obesity worldwide: international survey. BMJ 2000; 320:1-6.

22. World Health Organization. Oral health surveys: basic methods. $4^{\text {th }}$ Ed. Geneva: World Health Organization; 1997.

23. Ainamo J, Bay I. Problems and proposals for recording gingivitis and plaque. Int Dent J 1975; 25:229-35.

24. O'Brien M. Children's dental health in the United Kingdom 1993. London: Her Majesty's Stationery Office; 1994.

25. Dean HT. Classification of mottled enamel diagnosis. J Am Med Assoc 1934; 21:1421-6.
26. O'Sullivan EA. A new index for the measurement of erosion in children. Eur J Paediatr Dent 2000; 2:69-74.

27. A review of the developmental defects of dental index (DDE index). Int Dent J 1992; 42:411-26.

28. Heinrich-Weltzien R, Monse B, van Palenstein Helderman W. Black stain and dental caries in Filipino schoolchildren. Community Dent Oral Epidemiol 2009; 37:182-7.

29. Brasil. Espaços educativos. Ensino fundamental. Subsídio para elaboração de projetos e adequação de edificações escolares. Brasília: Fundo de For talecimento da Escola, Ministério da Educação e Cultura; 2002.

30. Organización Panamericana de la Salud. Escuelas promotoras de la salud: entornos saludables y me jor salud para las generaciones futuras. Washington DC: Organización Panamericana de la Salud; 1998.

31. Malikaew P, Watt RG, Sheiham A. Associations between school environments and childhood traumatic dental injuries. Oral Health Prev Dent 2003; 1:255-66.

32. Instituto Brasileiro de Geografia e Estatística. Pesquisa Nacional de Saúde do Escolar 2009. Rio de Janeiro: Instituto Brasileiro de Geografia e Estatística; 2009.

33. Kremer M, Reichert F, Hallal P. Intensidade e duração de esforços físicos em classes curriculares de Educação Física. Rev Saúde Pública 2012; 46:320-6

34. Marmot M, Wilkinson R. Social determinants of health. Oxford: Oxford University Press; 2006.

35. Levin KA. Study design III: cross-sectional studies. Evid Based Dent 2006; 7:24-5.

Submitted on 10/Sep/2012

Final version resubmitted on 11/Dec/2012

Approved on 20/Dec/2012 